\title{
A importância do ensino sobre gênero na graduação em Saúde Coletiva: uma interseção necessária
}

\section{The importance of teaching gender theory in undergraduate Public Health education: a necessary intersection}

\author{
Elaine Reis Brandão ${ }^{a}$ \\ (iD) https://orcid.org/0000-0002-3682-6985 \\ E-mail: brandao®iesc.ufrj.br \\ Fernanda Vecchi Alzuguira \\ (D) https://orcid.org/0000-0002-3162-5324 \\ E-mail: fevecchiळiesc.ufrj.br \\ anstituto de Estudos em Saúde Coletiva, Universidade Federal \\ do Rio de Janeiro. Rio de Janeiro, RJ, Brasil.
}

\section{Correspondência}

Elaine Reis Brandão

Universidade Federal do Rio de Janeiro, Instituto de Estudos em Saúde Coletiva. Av. Horácio Macedo, s/n, Cidade Universitária. Rio de Janeiro, RJ, Brasil. CEP 21941-598.

\section{Resumo}

O objetivo deste trabalho é refletir, a partir de nossa experiência como docentes do curso de graduação em Saúde Coletiva da Universidade Federal do Rio de Janeiro (UFRJ), sobre o ensino dos conteúdos relativos à problemática/às questões de gênero para estudantes em formação profissional na área da saúde. Acatando o desafio proposto neste dossiê, buscamos analisar como esse bacharelado per se, interdisciplinar - tem sido atravessado cotidiana e praticamente pelas ciências sociais, em particular pelas teorias que abordam o gênero como categoria analítica e importante ferramenta conceitual para uma compreensão crítica e política da realidade social. Acreditamos que tal aprendizado se torna imprescindível para uma atuação mais engajada com as desigualdades sociais em sentido lato (classe, raça/etnia, gênero), como a de futuros sanitaristas ou pesquisadores em saúde, tendo em vista o despertar do interesse e da sensibilidade discentes para o tema. A partir da conexão de suas próprias experiências e vivencias cotidianas como jovens, mulheres e homens, com pertencimentos étnico-raciais distintos, filiação de classe e inserção religiosa, temos assistido um processo de amadurecimento pessoal e profissional em nossos(as) estudantes que nos comprovam a fecundidade do ensino nessa direção.

Palavras-chave: Formação Profissional; Saúde Coletiva; Gênero; Ciências Sociais; Graduação em Saúde; Práticas Interdisciplinares. 
The objective of this study is to reflect, based on our experience as teachers of the undergraduate course in Public Health of the Federal University of Rio de Janeiro, on the teaching of gender issues for students under professional training in the health field. By accepting the challenge proposed in this dossier, we sought to analyze how this bachelor's degree-interdisciplinary by naturehas been explored daily and in a practical manner by social sciences, particularly by theories that approach the genre as an analytical category and an important conceptual tool for a critical and political understanding of social reality. We believe that such learning is essential for a more engaged action with social inequalities (class, race/ethnicity, gender) as future sanitarians or health researchers, in order to awaken students' interest and sensibility to the subject. Based on the connection between their own daily experiences as young people, women and men, with distinct ethnic and racial backgrounds, class affiliation and religious inclusion, we have witnessed a process of personal and professional maturity in our students, which proves us the fecundity of teaching in this manner.

Keywords: Professional Training; Public Health; Gender; Social Sciences; Undergraduate Studies in Health; Interdisciplinary Practices.
Nossa experiência como docentes na área da saúde coletiva há vários anos, desde a pós-graduação stricto e lato sensu até a graduação, empreendimento mais recente, com a aprovação dos cursos de graduação em Saúde Coletiva no Brasil, em 2008 (Lorena et al., 2016), incorpora nosso próprio processo de formação profissional como pesquisadoras e profissionais de saúde. Graduadas em Serviço Social e Psicologia, fomos igualmente convertidas às ciências sociais em nossa formação de pósgraduação - mestrado, doutorado, pós-doutorado -, o que nos transformou definitivamente como pessoas e ampliou sobremaneira o arsenal teórico e metodológico que dispúnhamos para ler, interpretar, conhecer e intervir no mundo social. A saúde coletiva foi nossa porta de entrada para as ciências sociais, para além da teoria marxista, ${ }^{1}$ e hoje, como docentes desse campo interdisciplinar, abraçamos o compromisso ético e político de trabalhar pela formação reflexiva e crítica de jovens estudantes a partir dessa matriz compreensiva. ${ }^{2}$

A formação em Ciências Sociais nos introduziu ao universo dos estudos de sexualidade e gênero (Aquino, 2006; Araújo; Schraiber; Cohen, 2011; França; Facchini, 2017; Heilborn; Sorj, 1999) ainda na década de 1990, conformando nossas trajetórias de pesquisa e de ensino na saúde. Aliado ao conceito de classe social, dominante nas teorias sociais dos anos 1970 e 1980, outra concepção igualmente reveladora das desigualdades sociais, como o gênero, transformou radicalmente nossa compreensão de processos de saúde e doença, que se estabelecem/ ancoram diferencialmente em corpos específicos, de homens, mulheres e pessoas trans. 0 potencial heurístico e analítico derivado do conceito de gênero - aplicado à dinâmica cotidiana dos serviços de atenção à saúde e do atendimento a usuários(as) e à forma como determinados sujeitos pensam, compreendem e (des)cuidam de seus corpos e sua saúde, além dos recursos sociais e comunitários que

1 Andrea Moraes Alves (2018) produziu importante reflexão sobre a apreensão do conceito de gênero no âmbito do curso de Serviço Social, no qual leciona na Universidade Federal do Rio de Janeiro (UFRJ).

2 Sobre a necessidade de engajamento ético e político dos pesquisadores, concomitante ao rigor teórico-metodológico na produção de conhecimentos científicos, cf. Carrara, França e Simões (2018). 
acionam para enfrentar o adoecimento e ativarem redes de cuidado, em prol do restabelecimento da saúde - nos permite desvendar estratégias particulares e modos de viver e cuidar, tanto no espaço público quanto no privado.

Nos últimos anos, as críticas advindas das produções acadêmicas de feministas negras (Carneiro, 2016; Davis, 2016; Gonzalez, 2016), a partir dos estudos interseccionais (Biroli; Miguel, 2015; Hirata, 2014; Moutinho, 2014), nos conduziram a ampliar e incluir a discussão sobre o racismo institucional e nas práticas de saúde como componente essencial das discriminações sofridas pelos sujeitos em seus itinerários em busca de atenção e cuidados em saúde. Pensar e ensinar sobre a compreensão das desigualdades sociais em saúde (Barata, 2009; Barreira, 2014) significa trazer a estudantes as ferramentas teóricas e metodológicas que os(as) permitem realizar o cruzamento desses marcadores sociais das diferenças com os indicadores de saúde tradicionalmente usados no campo da saúde coletiva, como morbidade, mortalidade, expectativa de vida e fecundidade, entre outros.

Assim, nosso objetivo neste trabalho será refletir, a partir de nossa experiência como docentes do curso de graduação em Saúde Coletiva da Universidade Federal do Rio de Janeiro (UFRJ), sobre o ensino dos conteúdos relativos à problemática/às questões de gênero para estudantes em formação profissional na área da saúde. Acatando o desafio proposto neste dossiê, buscamos analisar como esse bacharelado - per se, interdisciplinar - tem sido atravessado cotidiana e praticamente pelas ciências sociais, em particular, pelas teorias que abordam o gênero como categoria analítica e importante ferramenta conceitual para uma compreensão crítica e política da realidade social. Acreditamos que tal aprendizado se torna imprescindível para uma atuação mais engajada com as desigualdades sociais em sentido lato (classe, raça/etnia, gênero) da parte de futuros sanitaristas ou pesquisadores em saúde, tendo em vista o despertar do interesse e da sensibilidade discentes para o tema.
A oferta de tal disciplina tem sido uma escolha estratégica por nós adotada diante do contexto sociopolítico das políticas antigênero em curso na América Latina e no Brasil. Diante do conservadorismo moral e religioso, hoje imperante no Congresso Nacional e no Poder Executivo do país, é urgente problematizarmos no espaço da universidade pública as raízes do que se denomina equivocadamente "ideologia de gênero" (Corrêa, 2018; Miskolci; Campana, 2017). Como as mídias sociais reproduzem e proliferam falsos conteúdos acerca desse debate, tem sido importante trazer à sala de aula os mecanismos que obscurecem e deturpam processos de aprendizado que vinham se desenvolvendo sobre diversidade sexual e de gênero ao longo das últimas décadas, a partir de uma expansão das políticas públicas de educação, saúde e proteção aos direitos humanos.

\section{A disciplina de Gênero e Saúde no curso de graduação em Saúde Coletiva}

A nossa parceria intelectual acerca da temática de gênero na graduação em Saúde Coletiva se iniciou formalmente por meio de um curso de extensão que passamos a ofertar regularmente no Instituto de Estudos em Saúde Coletiva (Iesc) da UFRJ a partir de 2015, voltado a profissionais de saúde, pesquisadores, integrantes de movimentos sociais e organizações não governamentais (ONG) vinculadas à saúde e estudantes de graduação e pós-graduação de diversas áreas (Ciências da Saúde, Ciências Sociais, Psicologia, Serviço Social etc.). O curso de extensão Medicalização do Corpo: Contribuições da Problemática de Gênero para os Processos de Saúde e Doença, ${ }^{3}$ com 32 horas-aula, sempre teve ampla procura, com estudantes vindo inclusive de fora do Rio de Janeiro (São Paulo, Florianópolis, Campos dos Goytacazes, Petrópolis) para prestigiálo. Em suas edições de 2015 e 2017, reuniu um total de 8o participantes, que o concluíram. 0 curso se propõe a subsidiar a fundamentação e

\footnotetext{
3 Agradecemos ao colega Lucas Tramontano pela parceria na coordenação do último curso de extensão, em 2017, e a Maria Eduarda Brandão Mendes Pedroso de Lima, graduanda em Saúde Coletiva, pelo apoio na organização dos eventos, bem como aos colegas convidados que estiveram conosco nas edições até o momento realizadas no Instituto de Estudos em Saúde Coletiva (Iesc) da UFRJ: Ana Cristina Pimentel, Daniela Manica, Georgia Pereira, Marina Nucci e Rogério L. Azize.
} 
reflexão crítica sobre a práxis de participantes e, assim, indagar de que maneira "a problemática de gênero se articula às concepções e práticas sobre saúde e doença, com ênfase especial nos processos reprodutivos e de medicalização dos corpos 'femininos' e 'masculinos', produção de diagnósticos e medicamentos" (Alzuguir; Brandão, [2017]). A avaliação positiva acerca da oferta desse curso de extensão, uma modalidade de aperfeiçoamento profissional gratuita disponível nas universidades públicas, consolidou nosso interesse em ofertar a disciplina optativa Gênero e Saúde (ISCoo4), ${ }^{4}$ de 30 horas-aula, a estudantes não só da graduação em Saúde Coletiva, mas também de outros cursos da universidade com interesse nessa temática. Pelo fato de já trabalharmos como pesquisadoras nessa temática, de haver outras colegas de departamento ${ }^{5}$ de ciências sociais e humanas em saúde que também trabalhavam com a temática, na perspectiva dos direitos humanos, e de existir uma demanda discente do centro acadêmico, que solicitava a oferta da disciplina, após algum tempo de sua interrupção, sua aprovação no colegiado de graduação foi bastante tranquila. Também acreditamos que haja no corpo docente da saúde coletiva relativo consenso sobre a importância estratégica de tal abordagem diante dos desafios da formação dos profissionais de saúde.

Por ser uma disciplina optativa, o obstáculo que temos enfrentado atualmente é conseguir ofertá-la em um dia da semana mais livre na grade curricular do curso, uma vez que alunos(as) estão envolvidos em estágios, disciplinas e atividades de extensão. Após consulta extensa ao corpo discente sobre o melhor dia para o curso e aprovação pelo colegiado da instituição, ele está sendo ministrado nas manhãs de sexta-feira.

A ementa da disciplina versa sobre "a introdução ao campo dos estudos de gênero e suas repercussões na saúde coletiva, incluindo aspectos históricos, conceituais, metodológicos e assistenciais" (Brandão; Alzuguir, 2019, p. 1). Conforme nossas trajetórias de pesquisa, alguns eixos de análise foram eleitos para desdobramentos na disciplina, quais sejam, direitos sexuais e reprodutivos, processo de medicalização da vida social e implicações do conceito de gênero para os estudos sociais da ciência e da tecnologia. 0 curso tem sido ofertado por meio de dois módulos: o primeiro mais conceitual e o segundo mais aplicado à área da saúde, com trabalhos que problematizam tal perspectiva para analisar contextos empíricos específicos, como alcoolismo, epidemia do zika vírus, contracepção etc. No objetivo geral dessa disciplina, consta:

Apresentar conceitos fundamentais da área dos estudos de gênero, os quais estruturam o modo de reflexão e de organização da vida social, de modo que os/as aluno/as compreendam a importância deste tema e suas repercussões nas representações e práticas de saúde. (Brandão; Alzuguir, 2019, p. 1)

Como objetivos específicos desse empreendimento educativo, delimitamos:

1) Estimular a reflexão sobre a importância da categoria de gênero, em associação a outros marcadores de diferença social, como classe, raça/etnia, geração, na constituição e expressão de processos de saúde e doença; 2) Propiciar a compreensão do processo de medicalização e farmacologização da vida social, em estreita articulação com marcadores de gênero; 3) Identificar ferramentas teóricas e de intervenção que o conhecimento do tema permite para a intervenção profissional do sanitarista no campo da saúde. (Brandão; Alzuguir, 2019, p. 1)

Desde então, temos observado o enorme interesse e entusiasmo de jovens alunas(os) com os debates em sala de aula, os quais perpassam temas diversos, como alcoolismo, transexualidade, prostituição, contracepção, uso de medicamentos e outras substâncias, violência, mercado de trabalho e produção científica, maternidade e deficiências todos igualmente atravessados pelas hierarquias de gênero. A experiência pregressa de formação de

4 Essa disciplina foi ofertada durante muitos anos na graduação em Saúde Coletiva do Iesc-UFRJ pela professora Regina Helena Simões Barbosa antes de assumirmos a cadeira, após sua aposentadoria da universidade.

5 No Iesc-UFRJ, não temos departamentos, e sim áreas temáticas. 
profissionais de ciências sociais e humanas e de ciências da saúde na pós-graduação, latu ${ }^{6}$ ou stricto sensu (Ferreira; Brandão, 2019), nos qualificou e nos motivou a sensibilizar futuros(as) sanitaristas para a necessária problematização das questões inerentes ao gênero, à sexualidade e à raça no âmbito das chamadas vigilâncias em saúde (epidemiológica, ambiental e nutricional, dentre outras). Independentemente dos espaços de atuação desses(as) futuros(as) sanitaristas se nas comunidades, a partir da Estratégia de Saúde da Família, na atenção básica, nos setores de imunizações, no planejamento de programas e políticas públicas, em ações de monitoramento em saúde, na atenção hospitalar ou com os movimentos sociais, enfim, em diversas frentes de atuação profissional -, torna-se imprescindível aliar a reflexão sobre gênero a outras desigualdades que igualmente produzem as condições sociais de adoecimento que os usuários do Sistema Único de Saúde (SUS) enfrentam em seu cotidiano de vida e trabalho.

\section{O gênero como uma lente para compreensão do mundo social}

Mas, afinal, o que entendemos por gênero? Do que estamos falando quando enfatizamos tal perspectiva de análise social como potente ferramenta teórica e metodológica na saúde coletiva? Desde Joan Scott (1995, 2012), Gayle Rubin (1975, 1984), Georges Duby e Michelle Perrot (1991), Françoise Héritier (1996, 2002), Nicole-Claude Mathieu (2009), Donna Haraway (1995) e Emily Martin (2006) até Judith Butler (2003), o campo dos estudos de gênero e, mais recentemente, dos estudos interseccionais e estudos sociais da ciência e tecnologia - Fausto-Sterling (2000), Fonseca et al. (2012), Jasanoff (2004), Oudshoorn (1994), Schiebinger (2001) e Wijngaard (1997), entre outros - cresceram assustadoramente, nos obrigando a fazer muitas inflexões em nossa forma de compreensão dos corpos, dos sujeitos e das dimensões naturais e socioculturais que os modelam em suas experiências de saúde e doença. Se Michel Foucault (1988) ilumina nossos caminhos para pensar os "dispositivos de sexualidade" sob nova abordagem, enfatizando os dispositivos institucionais que colocam o "sexo em discurso", essas autoras nos colocam a dimensão do gênero como estruturante da organização social, cindindo entre masculino e feminino nossa apreensão do mundo social, hierarquicamente ordenado com subordinação do feminino ao masculino. 0 processo de atribuição de sentido ou o ato de interpretar socialmente a diferença sexual instaurada nos corpos de homens e mulheres (Laqueur, 2001) dá margens para uma classificação social dos atributos quer como femininos ou como masculinos, como se a "ordem natural" imanada dos corpos, assim produzidos e demarcados, fosse o sustentáculo da “ordem social”, hierarquicamente organizada com predominância do valor positivo ao masculino. Com o tempo, cada vez mais as teorias de gênero problematizam as dimensões simbólicas e materiais que concebem novas experiências subjetivas, novos desejos e novas mutações corporais, rompendo com a compreensão binaria antes prevalente.

Considerando o caráter interdisciplinar de nossa trajetória de pesquisa e ensino e as transformações mais amplas no campo do conhecimento que a acompanha, a perspectiva de gênero que abraçamos, portanto, está profundamente afetada pelas reflexões e confluências advindas dos estudos sociais da ciência e tecnologia e dos estudos de gênero. Nesse aspecto, alinha-se às discussões da vertente de estudos interessada nas intrincadas relações entre gênero e ciência, ou seja, nas implicações do gênero sob a própria produção do conhecimento cientifico acerca da diferença sexual. Nossas reflexões consideram as contribuições de estudiosas que, posicionadas a partir de "dentro"

\footnotetext{
6 Ambas as autoras tiveram extensa experiência de formação de outros profissionais de ciências sociais, ciências humanas e ciências da saúde em cursos de aperfeiçoamento e/ou especialização em sexualidade e gênero no Instituto de Medicina Social da Universidade do Estado do Rio de Janeiro, onde atuaram: no Programa Interinstitucional de Treinamento em Metodologia de Pesquisa em Gênero, Sexualidade e Saúde Reprodutiva (Aquino et al., 2003), ofertado durante os anos de 1996 a 2008, sob coordenação de Maria Luiza Heilborn; na elaboração de conteúdo do curso semipresencial de Especialização em Gênero e Sexualidade (EGeS), do Centro Latino-Americano em Sexualidade e Direitos Humanos no caso de Brandão; e na coordenação dessa mesma formação em âmbito nacional, no período de 2013 a 2014; e na prática docente (cursos EGeS e Gênero e Diversidade na Escola, na primeira década dos anos 20oo), no caso de Alzuguir.
} 
das ciências "naturais", como é o caso das ciências biológicas, problematizam a clássica polarização entre sexo/corpo/natureza e gênero/cultura, que delimita ainda as fronteiras entre os campos de investigação dos estudos das ciências naturais e humanas, respectivamente. Corpo e sexo eram domínios restritos às ciências biomédicas, enquanto as ciências sociais se ocupavam dos determinantes socioculturais que incidiam sobre uma suposta realidade biológica imutável (corpo), "autoevidente" (Alzuguir; Nucci, 2015).

Nesse grupo de estudiosas, situam-se as chamadas "feministas biólogas", pesquisadoras formadas na área das ciências naturais interessadas em "rever a história do gênero na biologia da diferenciação sexual, mostrando como o que é definido como 'natural', 'biológico' e ‘imutável' está permeado pelas concepções de gênero dominantes de nossa sociedade" (Carrara et al., 2010, p. 29). Nessa vertente, podemos citar autoras como Anne FaustoSterling, Donna Haraway, Marianne Wijngaard e Nelly Oudshoorn, entre outras.

Essa visão coloca em questão as bases do determinismo biológico, sobre o qual as desigualdades sociais de gênero historicamente se assentam e se justificam. Nessa perspectiva, pensar gênero implica inevitavelmente a análise do corpo e do sexo como domínios inscritos e moldados por processos socio-históricos, como Laqueur (2001) evidencia a respeito da passagem do modelo do sexo único ao modelo dos dois sexos irredutíveis e complementares, a partir do século XVIII. Podemos dizer que o dimorfismo sexual constitui o "estilo de pensamento" (Fleck, 2010) vigente, que orienta a construção do gênero e a biopolítica da vida contemporânea, permeando as investigações científicas em campos como neurociência, genética e biologia reprodutiva, as práticas terapêuticas (farmacoterapias e cirurgias estéticas, entre outras) e a produção de artefatos tecnológicos os mais diversos.

A perspectiva que adotamos, portanto, amparadas pelo olhar das ciências sociais, interroga sobre os modos de produção das diferenças de gênero e das desigualdades sociais tomando o corpo, o sexo, a biologia e a natureza como domínios de análise de modo algum autoevidentes, pois são produzidos e inevitavelmente enredados em dinâmicos arranjos sociais e locais.

Tal problematização torna-se necessária e urgente no âmbito das ciências da saúde. Para além do conteúdo e da abordagem teórica, quando ofertamos a disciplina de gênero e saúde para graduandos em Saúde Coletiva, estávamos cientes do desafio de "como" transmitir e sensibilizar iniciantes para esse tipo de conhecimento, que pressupõe um modo particular de olhar e a desnaturalização de formas de pensar o outro e a si mesmo em um contexto social particular.

Podemos dizer que a desnaturalização pretendida se faz na contramão de uma visão positivista ainda bastante presente nas ciências biomédicas, que se apoia na ideia de que as "descobertas" científicas sobre a "natureza" ocorrem espontaneamente aos olhos do(a) pesquisador(a), sem que haja qualquer interferência da cultura sobre esse olhar. Nossa perspectiva, longe de destituir o empreendimento científico - do qual inclusive fazemos parte -, está alinhada às considerações de Haraway (1995) sobre o caráter situado, social, histórico e inevitavelmente parcial do conhecimento. Confrontar a neutralidade do conhecimento científico, evidenciando seu enredamento em processos sociais e históricos, não significa, contudo, abandonar a objetividade desse conhecimento, o que incrementa ainda mais nossa responsabilidade pelo que produzimos.

\section{0 aprendizado discente em gênero e saúde}

A disciplina de Gênero e Saúde está sendo ofertada pela segunda vez no primeiro semestre de 2019. Na primeira turma, no primeiro semestre de 2018, recebemos seis alunas, cinco da graduação em Saúde Coletiva e uma da Biomedicina da UFRJ. Na segunda turma, em andamento, temos 11 estudantes, oito alunas e três alunos; a maioria da turma é negra, três deles são da graduação em Educação Física, uma das Ciências Sociais e o restante da Saúde Coletiva, de diversos períodos ao longo da graduação. Neste ano de 2019, três alunas da pósgraduação em Saúde Coletiva, duas mestrandas e uma doutoranda, nossas orientandas, acompanham o curso, desenvolvendo seu treinamento em "práticas didáticas" - duas delas como bolsistas 
da Coordenação de Aperfeiçoamento de Pessoal de Nível Superior (Capes). A presença delas também contribui para dinamizar as atividades em sala de aula: na medida em que apresentam seus projetos de pesquisa, são incumbidas de preparar exposições temáticas e participam no debate com os(as) graduandos(as). A avaliação do curso se dá mediante leitura da bibliografia indicada, participação nos debates em sala de aula e realização de um trabalho final, individual e escrito, sobre o conteúdo da disciplina, articulado a algum tema de interesse do(a) estudante. Esse trabalho tem sido o estopim para futuros interesses de aprofundamento no tema, transformando-se, em alguns momentos, no pontapé inicial das respectivas monografias de conclusão de curso de graduação em Saúde Coletiva.

A partir do retorno de discentes que frequentaram a disciplina, algumas das quais foram por nós orientadas em seus trabalhos de conclusão de curso, ${ }^{7}$ temos podido acompanhar a ampliação do interesse e da capacidade de articulação da temática de gênero para refletir criticamente sobre o cotidiano das práticas de saúde. Tal observação se expressa em campos de estágios, em atividades extracurriculares e de extensão e nas demais disciplinas do curso de graduação que abordam outras dimensões sociológicas importantes, como Saúde e Sociedade e Ciência e Saúde Coletiva, que igualmente ministramos, bem como em Determinantes Sociais em Saúde, Atividades Integradas em Saúde Coletiva, ${ }^{8}$ Educação em Saúde, Metodologia Qualitativa de Investigação Social em Saúde, Ciclos de Vida e Saúde e Direito Sanitário, todas ofertadas por docentes vinculadas à área de ciências sociais e humanas em saúde do Instituto. Observamos que a participação nessas disciplinas tem também despertado o interesse discente em cursar Gênero e Saúde para aprofundar essa reflexão. Uma aluna que cursava no mesmo período as disciplinas Gênero e Saúde e Metodologia Qualitativa relatou que as reflexões sobre gênero permitiram a ela depurar o olhar para as práticas em saúde em sua vivência de estágio em uma maternidade, pois começou a indagar sobre os fatores socioculturais que influenciam o acesso ao procedimento do aborto legal. Tal indagação resultou na escolha do aborto legal como tema para o projeto final da disciplina de Metodologia Qualitativa.

Também tem sido curioso notar que alunas dos cursos de Biomedicina, Nutrição, Educação Física e Fonoaudiologia da UFRJ têm nos procurado para frequentar a disciplina ou para a orientação de monografias, no intuito de iniciarem uma reflexão mais sistemática que possa incorporar o gênero em suas práticas laboratoriais, de ensino ou de atendimento clínico. Sabemos ser incipiente nos cursos de área biomédica tal reflexão, porém percebemos que o debate instaurado na sociedade civil, nos últimos anos, em torno de temas como violência sexual e de gênero, aborto, assédio sexual e moral, racismo, homofobia, feminicídio e ensino do gênero na educação tem impactado sobremaneira as gerações mais jovens, que sentem na pele tais discriminações sociais.

O contato com discentes ao longo de nosso percurso docente pelas disciplinas de graduação em Saúde Coletiva nos permite levantar determinados aspectos socioculturais que são compartilhados por uma parcela significativa do corpo discente: estes são, em sua maioria jovens, provenientes de famílias evangélicas, com baixo poder aquisitivo e moradores da zona norte carioca ou da Baixada Fluminense, além daqueles vindos de outros estados

7 Algumas alunas do curso de graduação em Saúde Coletiva têm abraçado a tarefa de produzir sua monografia de conclusão de curso delineando objetos de estudo, no campo da saúde, que se entrecruzam com a perspectiva de gênero. Exemplos podem ser dados de alunas por nós orientadas: Gênero e saúde no contexto escolar: as representações sociais de gênero nos cadernos pedagógicos de ciências da rede municipal do Rio de Janeiro, de Camila Fernandes Mesquita (2015); "Mãe, proteja seu bebê da AIDS": concepções de gênero e saúde em materiais educativos sobre prevenção das DST/AIDS, de Bianca Silva de Pontes (2016); "Os caras”: estereótipos de homens e masculinidades nos materiais de prevenção de DST/Aids, de Kelly Cristina da Silva Cunha (2017); "Não é competência do professor ser sexólogo": o debate público recente sobre gênero e sexualidade no Plano Nacional de Educação, de Rebecca Faray Ferreira Lopes (2017); Controvérsias no debate público sobre a vacina contra HPV, de Larissa Nunes Moreira Reis (2018); e Gênero e atenção primária à saúde: uma revisão crítica da literatura na saúde coletiva, de Lívia Gonçalves Rabelo Araújo (2019).

8 Há, neste dossiê, outro artigo de colegas do Iesc/UFRJ que aborda a experiência docente na disciplina Atividades Integradas em Saúde Coletiva II, intitulado "Dilemas atuais da sociedade brasileira sob as lentes da antropologia: relato de experiência de uma disciplina do curso de graduação em saúde coletiva da UFRJ”, de Ferreira, Tramontano e Klein. 
da Federação. Embora seja visível a presença maior de alunas na graduação em Saúde Coletiva, parece haver um contingente crescente de alunos ingressando na graduação. ${ }^{9}$

\section{Desnaturalizando diferenças e desigualdades sociais a partir do aprendizado de gênero: uma ruptura necessária}

No caso especifico da disciplina Gênero e Saúde, a reflexão crítica requer a desnaturalização dos pressupostos que fundamentam a diferença de gênero, a exemplo da aparente fixidez da relação entre sexo e gênero e do determinismo biológico que legitima e justifica historicamente não só a desigualdade social entre homens e mulheres, mas também entre comportamentos, desejos e modos de ser que contrariam o clássico binarismo a serviço da lógica heteronormativa.

A proposta de desnaturalização de relações sociais a partir do aprendizado de gênero é desafiadora, pois implica romper com interpretações e expectativas erigidas pelo senso comum sobre as relações entre homens e mulheres, que foram gradativamente inscritas e incorporadas no modus operandi das instituições sociais e nos corpos por meio do processo socializador e que se expressam pela aquisição do habitus (Bourdieu, 2009). Assim, mais do que uma simples transmissão de conteúdo a respeito do gênero, nossa proposta pretende sensibilizar graduandos em Saúde Coletiva para "um modo sociológico de pensar" (Barreira, 2014, p. 66), o qual "supõe a tarefa de instrumentalizar os alunos com categorias analíticas e maneiras de observar o que é designado como 'realidade social', de modo diferente daquele utilizado costumeiramente para explicar o mundo e nele situar".

Esse modo diferenciado de pensar implica perceber os fenômenos sociais como inextrincavelmente enredados em processos históricos, que somente podem ser compreendidos a partir de um exercício de contextualização dos vetores sociais em jogo. Isso pressupõe a ruptura com explicações lineares e simplistas do tipo causa e efeito sobre os fenômenos sociais e com as que evocam a influência de uma ordem supostamente natural para interpretálos (Barreira, 2014). Trata-se de problematizar o referido determinismo biológico, ancorado em um corpo supostamente natural que historicamente tem servido de lócus privilegiado para explicar e justificar diferenças e desigualdades sexuais, étnico-raciais e de gênero - e, assim, compreender que “a biologia não é destino", evidenciando o caráter atual da célebre frase da filósofa francesa Simone de Beauvoir, de que "não se nasce mulher, torna-se mulher"1o (Beauvoir, 1980a, 1980b). Nos dizeres de Barreira (2014, p. 68),

É importante lembrar que parte considerável do pensamento instituído - denominado ideologia firmou suas convicções afirmando que os fatos são naturais e não sociais. É o caso da ocultação ou naturalização das diferenças de gênero, de etnia, de classe e geração, muitas vezes explicadas com base em supostos biológicos percebidos como forças motrizes do comportamento humano.

Essa discussão já se inicia no primeiro módulo da disciplina Introdução ao Conceito de Gênero como Categoria Analítica e Política, no qual se evidencia amparado por uma bibliografia básica de introdução ao conceito - que ele tem uma história, sendo ele próprio resultado de um diálogo entre o movimento feminista e suas teóricas e pesquisadoras de áreas das ciências sociais e humanas, como história, ciência política e sociologia, entre outras. Além disso, falamos sobre a variabilidade cultural do gênero a partir de exemplos sobre formas de organização não ocidentais e de seu caráter relacional, o que requer mostrar que gênero como categoria analítica difere de uma concepção descritiva que o associa diretamente ao sexo biológico, a exemplo

\footnotetext{
9 Tais informações são bastante genéricas, pois oriundas de nossa observação acumulada na experiência docente. Assim, ainda que a maioria das discentes sejam jovens alunas, também observamos a presença de alunos e alunas mais velhos, normalmente egressos de uma graduação anterior ou atuantes, no passado ou no presente, profissionalmente na área da saúde como técnicos ou auxiliares de enfermagem, por exemplo. Por isso, há necessidade de um estudo sobre o perfil sociodemográfico dos alunos da graduação em Saúde Coletiva, para melhor caracterização desse público.

10 Assim como, podemos dizer, "ninguém nasce homem, torna-se homem".
} 
da identificação ainda bastante comum dele como sinônimo de mulheres. Tentamos transpor essa questão, evidenciando a historicidade da relação entre sexo e gênero. Percebemos como a problematização dessa equivalência é importante no campo da saúde, considerando a existência de inúmeros estudos que pretendem realizar um levantamento sociodemográfico sobre a realidade sanitária de determinado território e que tomam inadvertidamente o sexo biológico pelo gênero na descrição sobre o "público-alvo" e na análise dos resultados.

Consideramos que os trabalhos que articulam gênero a partir da problematização das condições de produção do conhecimento científico (Laqueur, 2001; Martin, 2006; Schiebinger, 2001) nos ajudam de modo importante na dupla tarefa simultânea de contextualização do gênero na história e de desnaturalização da diferença sexual, que pensamos ser indispensável para a construção de um olhar crítico sobre o gênero em sua relação com a saúde. Desse modo, trata-se de mostrar que a produção do conhecimento e a própria ideia de natureza que dela resulta (a qual se atrela o “sexo/corpo", em oposição ao "gênero/cultura") não é neutra e nem isenta de valores, e que, dessa maneira, precisa ser analisada sempre a partir de seu contexto social e político e dos campos de disputa em jogo.

Os estudos sobre gênero e ciência evidenciam como o olhar para as evidências científicas também não está imune aos estereótipos e construções de gênero, como Martin (1996) atesta tão bem em suas formulações a respeito dos pressupostos culturais de gênero que se apresentam no terreno impensado das narrativas cientificas dos livros de biologia reprodutiva sobre o processo de fecundação envolvendo o óvulo e o espermatozoide.

Sabemos que estamos diante de uma tarefa que nos desafia: apresentar pela primeira vez a estudantes de graduação na área da saúde a categoria de gênero como um constructo pelo qual - em sua íntima intersecção com outros marcadores sociais, como classe e raça/etnia em contextos específicos - é possível compreender a organização da sociedade em sua complexidade e, assim, refletir sobre a produção de desigualdade social e seu impacto na saúde.
Nossa experiência como docentes de graduação em Saúde Coletiva tem nos ensinado a importância de articular os conceitos com exemplos que remetam à realidade dos estudantes, de modo que façam sentido em sua dimensão teórico-prática. Desse modo, a partir da discussão teórico-conceitual sobre gênero, estimulamos a reflexão acerca, por exemplo, de como este produz diferenças e desigualdades nos campos de estágio em que estão inseridos, no acesso, na organização dos serviços e na diferença na forma como corpos femininos são medicalizados em comparação aos masculinos.

Barreira (2014) também evoca o desafio de lidar com o pragmatismo inerente às escolhas vocacionais, que se manifesta em indagações como “para que serve a disciplina de Sociologia?". No nosso caso, temos uma situação um pouco diferente, pois as(os) alunas(os) que nos procuram, embora sem conhecerem ainda o conceito, já demonstram algum tipo de inquietação e interesse em aprender sobre gênero, mesmo que não pareça ainda claro inicialmente para elas(es) de que modo tal arcabouço teórico-metodológico pode iluminar sua prática como sanitaristas ou profissionais de saúde.

Para o exercício de desconstrução inerente ao pensar sociológico, Barreira (2014) sugere como um caminho interessante o resgate de exemplos da vida cotidiana como recurso pedagógico para problematizar “verdades óbvias”. Nossa experiência tem mostrado que a abertura de um espaço de diálogo em sala sobre os acontecimentos mais corriqueiros da vida cotidiana é uma potente e rica estratégia de desnaturalização das forças sociais que instauram as assimetrias de gênero. Exemplos que destacam o processo de aprendizado do gênero pela socialização distinta entre homens e mulheres em ambientes como a casa, a escola, a universidade, os serviços de saúde etc. também são vias interessantes para elucidar a maneira como a diferenciação de gênero vai organizando a vida social. Assim, a bibliografia selecionada para cada aula acaba funcionando como uma espécie de disparador para esse debate sobre o cotidiano.

Ciente dessas questões, no programa da disciplina, após a parte mais conceitual e introdutória sobre gênero, indicamos, ao lado dos trabalhos acadêmicos, alguns textos atuais publicados em revistas, 
jornais, blogs e redes sociais e filmes de animação/ documentários. Tais recursos estimulam o debate sobre temas contemporâneos não apenas vinculados à saúde (epidemia do zika vírus, por exemplo), mas também encaixados dentro do enquadre mais amplo da maneira como gênero e sexualidade têm permeado a política brasileira em um cenário de retrocessos e ameaças às políticas públicas (a exemplo do SUS) e às conquistas decorrentes de um longo processo de lutas feministas e do movimento de lésbicas, gays, bissexuais, travestis, transexuais ou transgêneros, intersexos LGBT+ em direção à equidade de gênero e autonomia feminina reprodutiva.

Como exemplo, na primeira edição do curso, as alunas solicitaram a inclusão de temas que geram tensões morais entre setores religiosos, Estado e sociedade civil, como prostituição, pornografia, violência e tráfico de pessoas, o que foi por nós acolhido. No caso da prostituição de mulheres, o tema despertou um rico debate na turma sobre a profissionalização da atividade (evidenciando as diferentes vozes sobre o tema, inclusive entre feministas) e as questões relacionadas à perda ou ao ganho da autonomia das mulheres sobre seus corpos e sua sexualidade, articulados ao embate sobre violência de gênero e sexismo no contexto da prostituição.

Durante as aulas, as(os) aluna(os) evidenciam um importante processo de desconstrução provocado por essas reflexões, que extrapola o âmbito da formação profissional como sanitaristas, penetrando em suas vidas pessoais. Assim, se no início da disciplina podemos observar certo estranhamento ao constatarem que não há nada de "natural” na forma como o gênero organiza diferencialmente a gestão da vida pública e privada, por exemplo, há um momento em que começam a trazer mais abertamente, a partir de situações por elas(es) vivenciadas, o modo como a disciplina as(os) tem feito repensarem suas relações no âmbito da família, das redes virtuais e das relações afetivas.

Na primeira edição da disciplina, por exemplo, algumas alunas começaram a levar questionamentos sobre seu próprio processo de socialização no âmbito familiar. Uma delas comentou em sala, incomodada, que tem refletido sobre a distribuição desigual das tarefas domésticas entre ela e o irmão, uma vez que sua mãe a incumbe de arrumar a casa e o isenta dessas tarefas, embora tanto ela quanto ele ocupem um tempo significativo na dedicação com os estudos. Relatos como esse, aparentemente triviais, cresceram ao longo do curso e evidenciaram para nós a importância daquele espaço para as alunas, de modo a problematizarem e se reposicionarem diante das repercussões das expectativas sociais de gênero não como algo distante e alheio, mas que permeia e afeta suas vidas.

\section{Considerações finais}

Enfim, nossa experiência de ensino está em curso, em processo constante de reavaliação, a partir das demandas discentes. Somente por meio dessa interlocução podemos responder às inquietações dos alunos(as). Sem dúvida, essa troca entre docentes e estudantes nos alimenta e fortalece nosso desejo de permanecer resistentes diante das adversidades políticas que enfrentamos no cenário brasileiro atual. Testemunhamos inúmeros ataques ao SUS, às políticas públicas de educação e saúde, ao debate público sobre inclusão das temáticas de gênero e sexualidade nos planos de educação (Brandão; Lopes, 2018) e à inclusão de jovens cotistas nas universidades públicas. 0 acesso universal às políticas de educação e saúde, garantido na Constituição Federal de 1988, está sendo duramente criticado. O debate político instaurado no parlamento brasileiro sobre a chamada "ideologia de gênero" (Corrêa, 2018; Miskolci; Campana, 2017) deturpa e produz desinformação a respeito das conquistas celebradas nas últimas décadas em torno da aquisição de direitos sexuais e reprodutivos. Nosso desafio cresce a cada dia pelo fato de ministrarmos conteúdos centrais à construção de uma consciência crítica nos estudantes de graduação em torno da sociedade que vivemos, desigual, excludente, racista, homo e transfóbica e misógina. O curso de graduação em Saúde Coletiva enfrentará, a nosso ver, na próxima década de sua existência, seu maior desafio ou seja, se consolidar como uma via de qualificação profissional em meio ao conservadorismo político e moral vigente e ao backlash (Faludi, 1991) que assistimos no Brasil e em boa parte do contexto internacional. 
Nossa intenção é continuar ofertando a disciplina nos próximos anos, ampliando cada vez mais o modo de captação de alunos(as) de diferentes graduações que se interessem pelo tema, pois acreditamos que a troca entre práticas profissionais distintas enriquece o debate em sala de aula. No segundo semestre de 2019, ofertaremos a terceira edição do curso de extensão, que abrange estudantes e profissionais - e, no futuro próximo, temos o projeto de também elaborar um programa para ofertar a disciplina na pós-graduação stricto sensu em Saúde Coletiva. Temos um longo caminho pela frente. Seguimos motivadas pela certeza de que a reflexão crítica sobre gênero no âmbito da saúde é uma tarefa não só necessária como vital para o enfrentamento das desigualdades sociais no cenário político brasileiro atual.

\section{Referências}

ALVES, A. M. Pensar o gênero: diálogos com o serviço social. Serviço Social e Sociedade, São Paulo, n. 132, p. 268-286, 2018.

ALZUGUIR, F.; BRANDÃO, E. (Coords.). Medicalização do Corpo: Contribuições da Problemática de Gênero para os Processos de Saúde e Doença. Rio de Janeiro: Universidade Federal do Rio de Janeiro, [2017]. Programa de curso. Disponível em: <http://bit.ly/2UeFZG4>. Acesso em: 15 abr. 2019.

ALZUGUIR, F.; NUCCI, M. Maternidade mamífera? Concepções sobre natureza e ciência em uma rede social de mães. Mediações, Londrina, v. 20, n. 1, p. 217-238, 2015 .

AQUINO, E. M. L. Gênero e saúde: perfil e tendências da produção científica no Brasil.

Revista de Saúde Pública, São Paulo, v. 40, p. 121-132, 2006. Número especial.

AQUINO, E. M. L. et al. Gênero, sexualidade e saúde reprodutiva: a constituição de um novo campo na saúde coletiva. Cadernos de Saúde Pública, Rio de Janeiro, v. 19, p. S198-S199, 2003. Suplemento 2.

ARAÚJO, M. F; SCHRAIBER, L. B; COHEN, D. D. Penetração da perspectiva de gênero e análise crítica do desenvolvimento do conceito na produção científica da saúde coletiva. Interface: Comunicação, Saúde, Educação, Botucatu, v. 15, n. 38, p. 805-818, 2011.

BARATA, R. B. Como e por que as desigualdades sociais fazem mal à saúde. Rio de Janeiro:

Fiocruz, 2009.

BARREIRA, I. A. F. O ofício de ensinar para iniciantes: contribuições ao modo sociológico de pensar. Revista de Ciências Sociais, Fortaleza, v. 45 , n. 1, p. 63-85, 2014.

BEAUVOIR, S. O segundo sexo. Rio de Janeiro: Nova Fronteira, 1980a. v. 1.

BEAUVOIR, S. O segundo sexo. Rio de Janeiro: Nova Fronteira, 198ob. v. 2.

BIROLI, F.; MIGUEL, L. F. Gênero, raça, classe: opressões cruzadas e convergências na reprodução das desigualdades. Mediações, Londrina, v. 20 n. 2, p. 27-55, 2015.

BRANDÃO, E. R.; LOPES, R. F. F. "Não é competência do professor ser sexólogo": o debate público sobre gênero e sexualidade no Plano Nacional de Educação. Civitas, Porto Alegre, v. 18, n. 1, p. 100-123, 2018.

BRANDÃO, E. R.; ALZUGUIR, F. Programa da disciplina Gênero e Saúde (ISCoo4): graduação em Saúde Coletiva. Rio de Janeiro: UFRJ, 2019.

BOURDIEU, P. O senso prático. Petrópolis: Vozes, 2009. (Coleção Sociologia).

BUTLER, J. Problemas de gênero: feminismo e subversão da identidade. Rio de Janeiro:

Civilização Brasileira, 2003.

CARNEIRO, S. Mulheres em movimento. In: RODRIGUES, C.; BORGES, L.; RAMOS, T. R. O. (Orgs.). Problemas de gênero. Rio de Janeiro: Funarte, 2016. p. 149-168.

CARRARA, S.; FRANÇA, I. L., SIMÕES, J. A. Conhecimento e práticas científicas na esfera pública: antropologia, gênero e sexualidade. Revista de Antropologia, São Paulo, v. 61, n. 1, p. 71-82, 2018. 
CARRARA, S. et al. (Orgs.). Curso de especialização em gênero e sexualidade. Rio de Janeiro: Centro de Estudos e Pesquisa em Saúde Coletiva, 2010. v. 5.

CORRÊA, S. A "política do gênero": um comentário genealógico. Cadernos Pagu, Campinas, n. 53, 2018. Não paginado.

DAVIS, A. Mulheres, raça e classe. São Paulo: Boitempo, 2016.

DUBY, G.; PERROT, M. L'Histoire des femmes en Occident de l'Antiquité à nos jours. Paris: Plon, 1991.

FALUDI, S. Backlash: the undeclared war against women. New York: Crown, 1991.

FAUSTO-STERLING, A. Sexing the body. New York: Basic Books, 2000.

FERREIRA, J.; BRANDAO, E. R. Desafios da formação antropológica de profissionais de saúde: uma experiência de ensino na pós-graduação em Saúde Coletiva. Interface: Comunicação, Saúde, Educação, Botucatu, v. 23, 2019. Não paginado.

FONSECA, C. et al. Ciências na vida: antropologia da ciência em perspectiva. São Paulo: Terceiro Nome, 2012.

FOUCAULT, M. História da sexualidade: a vontade de saber. Rio de Janeiro: Graal, 1988. v. 1.

FLECK, L. Gênese e desenvolvimento de um fato científico. Belo Horizonte: Fabrefactum, 2010.

FRANÇA, I. L.; FACCHINI, R. Estudos de gênero no Brasil: 20 anos depois. In: MICELI, S.; MARTINS, C. B. (Orgs.). Sociologia brasileira hoje. São Paulo: Ateliê Editorial, 2017. p. 283-357.

GONZALEZ, L. A mulher negra na sociedade brasileira: uma abordagem político-econômica. In: RODRIGUES, C.; BORGES, L.; RAMOS, T. R. O. (Orgs.). Problemas de gênero. Rio de Janeiro: Funarte, 2016. p. 399-416.

HARAWAY, D. Saberes localizados: a questão da ciência para o feminismo e o privilégio da perspectiva parcial. Cadernos Pagu, Campinas, n. 5, p. 7-41, 1995 .

HEILBORN, M. L.; SORJ, B. Estudos de gênero no Brasil. In: MICELI, S. (Org.). O que ler na ciência social brasileira (1970-1995). São Paulo: Sumaré, 1999. p. 183-221.

HÉRITIER, F. Masculin/féminin: la pensée de la différence. Paris: Odile Jacob, 1996. v. 1.

HÉRITIER, F. Masculin/féminin: dissoudre la hiérarchie. Paris: Odile Jacob, 2002. v. 2.

HIRATA, H. Gênero, classe e raça: interseccionalidade e consubstancialidade das relações sociais. Tempo Social, São Paulo, v. 26, n. 1, p.61-73, 2014.

JASANOFF, S. The idiom of co-production. In: JASANOFF, S. (Ed.). States of knowledge: the coproduction of science and social order. New York: Routledge, 2004. p. 1-12.

LAQUEUR, T. Inventando o sexo: corpo e gênero dos gregos a Freud. Rio de Janeiro: RelumeDumará, 2001.

LORENA, A. et al. Graduação em saúde coletiva no Brasil: onde estão atuando os egressos dessa formação? Saúde e Sociedade, São Paulo, v. 25, n. 2, p. 369-38o, 2016.

MARTIN, E. The egg and the sperm: how science has constructed a romance based on stereotypical male-female roles. In: KELLER, E. F.; LONGINO, H. E. (Eds.). Feminism and science. New York: Oxford University Press, 1996. p. 103-120.

MARTIN, E. A mulher no corpo: uma análise cultural da reprodução. Rio de Janeiro: Garamond, 2006.

MATHIEU, N. C. Sexo e gênero. In: HIRATA, H. et al. (Orgs.). Dicionário crítico do feminismo. São Paulo: Editora da Unesp, 2009. p. 222-230.

MISKOLCI, R.; CAMPANA, M. "Ideologia de gênero": notas para a genealogia de um pânico moral contemporâneo. Sociedade e Estado, Brasília, DF, v. 32, n. 3, p. 725-747, 2017.

MOUTINHO, L. Diferenças e desigualdades negociadas: raça, sexualidade e gênero em produções acadêmicas recentes. Cadernos Pagu, Campinas, n. 42, p. 201-248, 2014.

OUDSHOORN, N. Beyond the natural body: an archelogy of sex hormones. London: Routledge, 1994. 
RUBIN, G. The traffic in women: notes on the "political economy" of sex. In: REITER, R. (Ed.). Toward an anthropology of women. New York: Monthly Review Press, 1975. p. 157-210.

RUBIN, G. Thinking sex: notes for a radical theory of the politics of sexuality. In: VANCE, C. (Org.). Pleasure and danger: exploring female sexuality. London: Pandora Press. 1984. p. 267-319.

SCHIEBINGER, L. O feminismo mudou a ciência? Bauru: Edusc, 2001.
SCOTT, J. Gênero: uma categoria útil para uma análise histórica. Educação \& Realidade, Porto Alegre, v. 20, n. 2. p. 71-99, 1995.

SCOTT, J. W. Usos e abusos do gênero. Projeto História, São Paulo, n. 45, p. 327-351, 2012. WIJNGAARD, M. Reinventing the sexes: the biomedical construction of femininity and masculinity. Bloomingtom: Indiana University Press, 1997.

\section{Contribuição dos autores}

Ambas as autoras participaram igualmente de todas as fases de elaboração e redação do manuscrito.

Recebido: $24 / 03 / 2019$

Aprovado: 28/03/2019 